\title{
Duodenal lymphocytosis with no or minimal enteropathy: much ado about nothing?
}

\author{
Gregory Y Lauwers ${ }^{1}$, Alessio Fasano ${ }^{2}$ and Ian S Brown ${ }^{3}$ \\ ${ }^{1}$ Gastrointestinal Pathology Service, Department of Pathology, Massachusetts General Hospital, Boston, MA, \\ USA; ${ }^{2}$ Division of Pediatric Gastroenterology and Nutrition, MassGeneral Hospital for Children, Boston, MA, \\ USA and ${ }^{3}$ Envoi Pathology, Brisbane, Queensland, Australia
}

\begin{abstract}
Duodenal lymphocytosis is a nonspecific finding that is being detected with heightened frequency. Although increased intraepithelial lymphocytosis with normal villous architecture classically corresponds to grade 1 of the Marsh classification, many other conditions have been reported to be associated with this histologic pattern. In this article, we offer a broad review of the associations of isolated increased intraepithelial lymphocytosis with celiac and nonceliac gluten sensitivity, as well as of the broadening nonceliac etiologies. Modern Pathology (2015) 28, S22-S29; doi:10.1038/modpathol.2014.135
\end{abstract}

The clinical presentation of gluten-sensitive enteropathy (GSE) has changed. More patients are diagnosed with less severe symptoms, and up to $40 \%$ are clinically silent. ${ }^{1}$ Anemia is a common finding in $8 \%$ of patients, whereas there is a decrease in the number of patients presenting with the classic symptom of diarrhea (43\% now compared with $73 \%$ before 1993). ${ }^{1}$ In fact, many patients may be misdiagnosed, with $5-30 \%$ of patients having been at some point diagnosed with irritable bowel syndrome. ${ }^{2,3}$

Duodenal lymphocytosis, that is, the increase of lymphocytes in the villous epithelial lining, has been debated in the literature over the last few years. During the last two decades, this diagnosis has been made with increasing frequency. This may have resulted from several converging dynamics. One is the recognition of an atypical presentation of GSE, including a preclinical stage that may present with minimal duodenal lymphocytosis; second, easier access to and increased use of some drugs (for example, NSAIDs) has been underscored; ${ }^{4}$ another is increased scrutiny from pathologists, which may have led to overinterpretation of duodenal lymphocytosis. However, in this review, we will attempt to clarify the diagnostic issues related to duodenal lymphocytosis and provide practical clues to direct the appropriate diagnosis and management of patients.

Correspondence: Dr GY Lauwers, MD, Gastrointestinal Pathology Service, Department of Pathology, Massachusetts General Hospital, 55 Fruit Street, WRN 219, Boston, MA 02114, USA.

E-mail: GLAUWERS@PARTNERS.ORG

Received 19 June 2014; revised 18 September 2014; accepted 18 September 2014
Normal Villus Architecture and Intraepithelial Lymphocyte Count

The gastrointestinal tract, with its large surface area and population of plasma cells, $\mathrm{T}$ and $\mathrm{B}$ lymphocytes, macrophages, and dendritic cells, is the largest lymphoid organ of the human body. Although most cellular components of the immune mucosal system rest in the lamina propria, the limited intraepithelial lymphocytes (IELs) are particularly significant, as they are the first cells to interact with any harmful luminal antigen, either infectious or alimentary. In the duodenum, the vast majority of IELs are phenotypically CD $8+\mathrm{T}$ cells expressing $\alpha / \beta$ T-cell receptors on the surface. ${ }^{5}$

Practically, whether evaluating the villous architecture or counting IELs, it is best not to assess biopsies that are not well oriented, as tangential sections can produce an artificial impression of increased IELs (and architectural abnormalities). Specifically, this may lead to inappropriate counting of lymphocytes adjacent to but located below the epithelial basement membrane and therefore in the lamina propria. This pitfall is particularly true when immunohistochemistry is used (see below). Thickness of the section is important as well, and it has been suggested that accurate evaluation requires well-oriented 3 - to $4-\mu$ sections. ${ }^{6,7}$

The upper limit of IELs in the normal proximal small bowel previously was considered to be 40/100 epithelial cells. However, this figure was based on counts performed on jejunal capsule biopsies, where IEL counts inherently are higher than in the duodenum. ${ }^{8}$ In more recent studies utilizing thincut sections and endoscopically obtained biopsies, several authors have shown the upper limit of 
normal for the duodenum to be 20-25 IELs/100 epithelial cells. ${ }^{6,7}$ It also has been emphasized that a greater density of IELs is seen in the crypts and, normally, a decrease in number from the base toward the tip is noted. ${ }^{9}$ Consequently, counting IELs at the tips of the villi and observing a lack of decrescendo from crypts to tips have been recommended as the most useful method of confirming an increase (Figure 1). ${ }^{9,10}$

Some authors have suggested that CD3 and CD8 immunohistochemistry can facilitate the detection of IELs, particularly as some lymphocytes can have an irregular nuclear outline mimicking granulocytes, and others could be mistaken for epithelial cell nuclei. ${ }^{11}$ It has been suggested that when immunohistochemistry is used, the upper limit of normal be increased to 30 per 100 IELs $^{6}$ before being considered pathologic. However, not all pathologists have found these additional stains helpful, cautioning that they decrease the sensitivity derived from appreciating a loss of the normal IEL decrescendo pattern. ${ }^{12}$

\section{Causes of Increased IELs in Architecturally Normal Duodenal Biopsies}

Given the location and proposed role of IELs, it is no surprise that the number of IELs can increase because of a variety of immunologic stimulants, whether by an ingested or endogenous antigen or via autoimmune causation. In fact, duodenal lymphocytosis once has been observed in between $1.3 \%^{13}$ and $2.2 \%{ }^{14}$ of patients undergoing upper GI tract endoscopy and small intestinal biopsy, and has been increasingly noted in up to $7 \%$ over the last 11 years in a singlecenter study of 15839 duodenal biopsies. ${ }^{4}$ However, it remains a vexing diagnostic problem, as a specific etiology is never discovered for many cases of duodenal lymphocytosis. ${ }^{13-16}$ (Tables 1 and 2) Nevertheless, a well-constructed report should emphasize a certain number of recognized associations to initiate a proper and timely clinical workup.

It should be stressed that a diagnosis of duodenal lymphocytosis does not represent a diagnosis of GSE, and, alternatively, a diagnosis of Marsh grade 1 lesion (that is, normal architecture with preserved crypt to villi ratio and increased IELs) applies only to patients with proven gluten-sensitive enteropathy (see below).

\section{Gluten-Sensitive Enteropathy}

Approximately $11 \%$ of patients with duodenal lymphocytosis test positive for IgA endomysial antibodies or antitissue transglutaminase, and onethird have the DQ2 allele associated with celiac disease. The prevalence of GSE in architecturally normal small intestinal biopsies and duodenal lymphocytosis has been reported to be $9-40 \%{ }^{13,14,17}$ Various terms are used in the

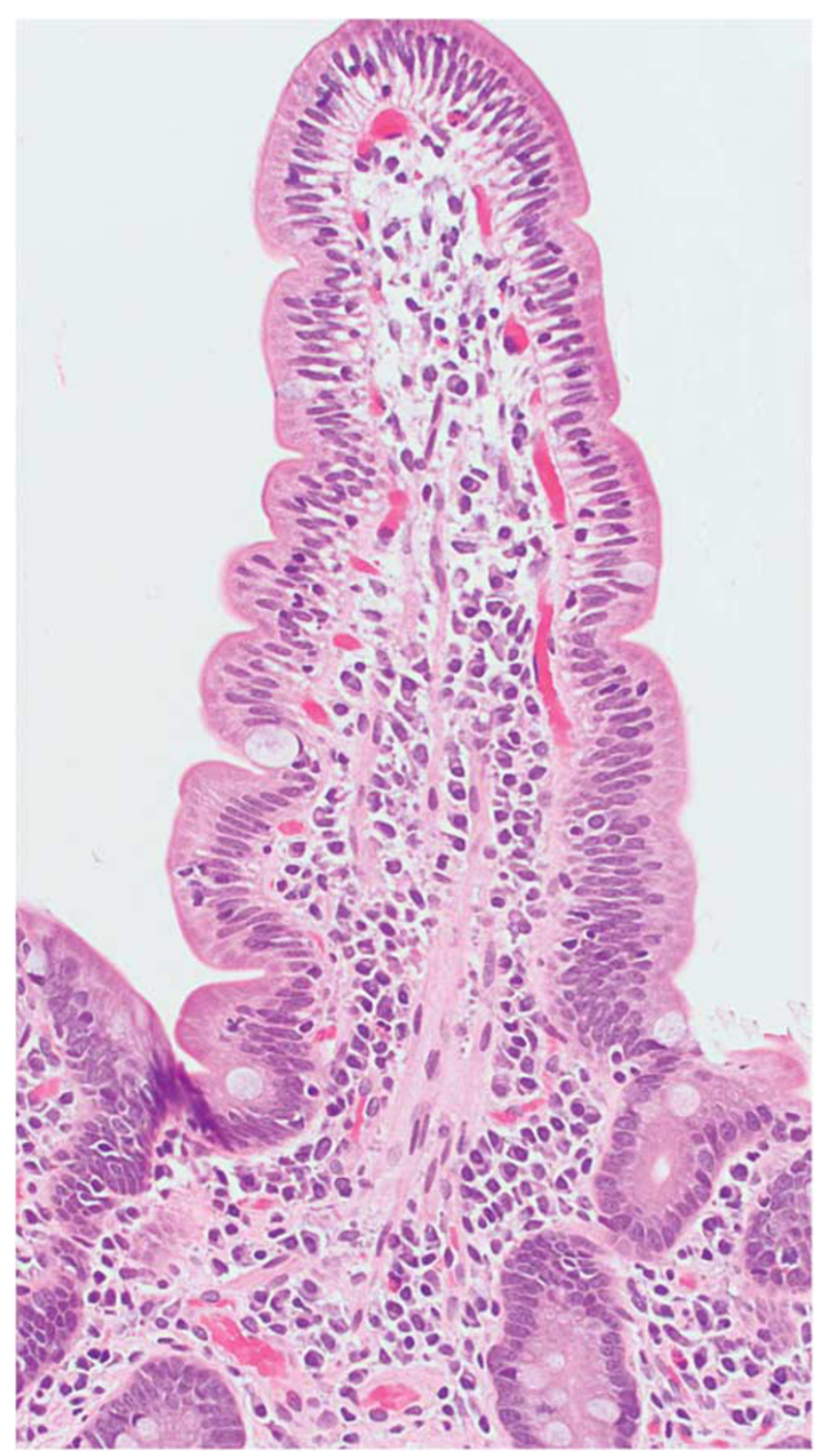

Figure 1 Normal duodenal villus. Only a few scattered lymphocytes are noted, well below 20 lymphocytes/100 epithelial cells.

literature to describe these patients: gluten sensitivity with mild enteropathy, latent celiac disease, and potential celiac disease. ${ }^{12}$

It has been reported that an even distribution of IELs along the villi, and thus a loss of the normal decrescendo pattern from base to tip of villi, is more likely to be associated with GSE than other etiologies. ${ }^{9,10,13,18}$ It is, however, a feature neither specific nor sensitive for gluten-related disorders (Figure 2).9,13

The use of immunohistochemistry is debated. It has been reported as helpful in highlighting the presence of increased IELs and the loss of decrescendo. ${ }^{11,12}$ However, the improved diagnostic specificity supported by some ${ }^{11,12,18}$ has been contested by others. ${ }^{19}$

It is important to note that these patients, even if presenting with mild morphological changes, can 
Table 1 Causes of proximal small intestinal intraepithelial lymphocytosis with normal villus architecture

Gluten-related disorders (celiac disease, nonceliac gluten sensitivity, wheat allergy)

Non-gluten food hypersensitivity (for example, cereals, cow's milk, soy products, fish, rice, and chicken)

Infections (for example, Giardia, Cryptosporidia, H. pylori, tropical sprue)

Bacterial overgrowth

Drugs (for example NSAIDs)

Immune dysregulation (for example, Hashimoto's thyroiditis, rheumatoid arthritis, SLE, and so on)

Immune deficiency (for example, IgA deficiency, CVID)

Inflammatory bowel disease (CD/UC)

Lymphocytic and collagenous colitis

GVHD

Preinfiltrative intestinal T-cell lymphoma

Idiopathic (including irritable bowel syndrome)

develop nutritional deficiencies leading to iron deficiency anemia and osteoporosis. ${ }^{20,21}$

For many years, small intestinal biopsies, supplemented by serological tests, have been held to be the gold standard of diagnosis of GSE. However, the optimal diagnostic sensitivity and specificity, as well as the high positive predictive value of IgA antihuman tissue transglutaminase and IgA endomysial antibody immunofluorescence, have led some to consider that histopathologic confirmation may not always be necessary in a subset of pediatric patients. ${ }^{22}$ However, the situation is different in Marsh type 1 injury pattern, since it is well established that the likelihood of a positive test correlates with the degree of mucosal injury, and GSE cases with intraepithelial lymphocytosis alone can often have antibody titers in the normal range. ${ }^{23-25}$ Thus, negative serology does not exclude a diagnosis of GSE with a Marsh type 1 pattern (that is, normal architecture with preserved crypt to villi ratio and increased IELs); a morphologic evaluation remains relevant.

Testing for HLA DQ haplotype is a mainstay of the diagnostic armamentarium. However, its usefulness is limited; a negative result makes a diagnosis of celiac disease very unlikely, but a positive test does not establish a diagnosis, in the context of duodenal lymphocytosis, because the DQ8/DQ2 haplotypes are seen in $25-40 \%$ of the general population. ${ }^{25,26}$ As other genes are believed to have a role in the development of GSE, many clinicians resort to a trial of gluten-free diet, or sometimes, a gluten challenge followed by rebiopsy.

\section{Nonceliac Gluten Sensitivity}

Despite being consistently testing negative for celiac disease serology, some individuals can develop a variety of symptoms related to wheat and/or gluten ingestion. Those with positive immunoglobulin E-mediated tests are diagnosed with wheat allergy; the others are considered to suffer from nonceliac
Table 2 Prevalence of conditions associated with duodenal intraepithelial lymphocytosis

\begin{tabular}{lccccc}
\hline & $\begin{array}{l}\text { Kakar }^{13} \\
(\mathrm{n}=43)\end{array}$ & $\begin{array}{c}\text { Mahadeva } \\
\text { (n=14) }\end{array}$ & $\begin{array}{c}\text { Hammer }^{16} \\
(\mathrm{n}=100\end{array}$ & $\begin{array}{c}\text { Shmidt }^{36} \\
(\mathrm{n}=48)\end{array}$ & $\begin{array}{c}\text { Aziz }^{15} \\
(\mathrm{n}=100)\end{array}$ \\
\hline $\begin{array}{l}\text { Celiac disease } \\
\text { Tropical }\end{array}$ & $9 \%$ & $21 \%$ & $18 \%$ & $19 \%$ & $16 \%$ \\
$\begin{array}{l}\text { sprue } \\
\text { H. pylori }\end{array}$ & $1 \%$ & - & $1 \%$ & - & - \\
$\begin{array}{l}\text { gastritis } \\
\text { Bacterial }\end{array}$ & $5 \%$ & - & $6 \%$ & $6 \%$ & $14 \%$ \\
$\begin{array}{l}\text { overgrowth } \\
\text { NSAIDs }\end{array}$ & $14 \%$ & - & $3 \%$ & - & - \\
$\begin{array}{l}\text { IBD } \\
\text { Autoimmune }\end{array}$ & $12 \%$ & - & $8 \%$ & $20 \%$ & $21 \%$ \\
conditions & $14 \%$ & - & $6 \%$ & - & $2 \%$ \\
$\begin{array}{l}\text { Unexplained } \\
\text { IBS }\end{array}$ & $7 \%$ & $21 \%$ & $26 \%$ & $33 \%$ & $34 \%$ \\
Other & $9 \%$ & $14 \%$ & $20 \%$ & - & - \\
\hline & $28 \%$ & $43 \%$ & $4 \%$ & $11 \%$ & $9 \%$ \\
\hline
\end{tabular}

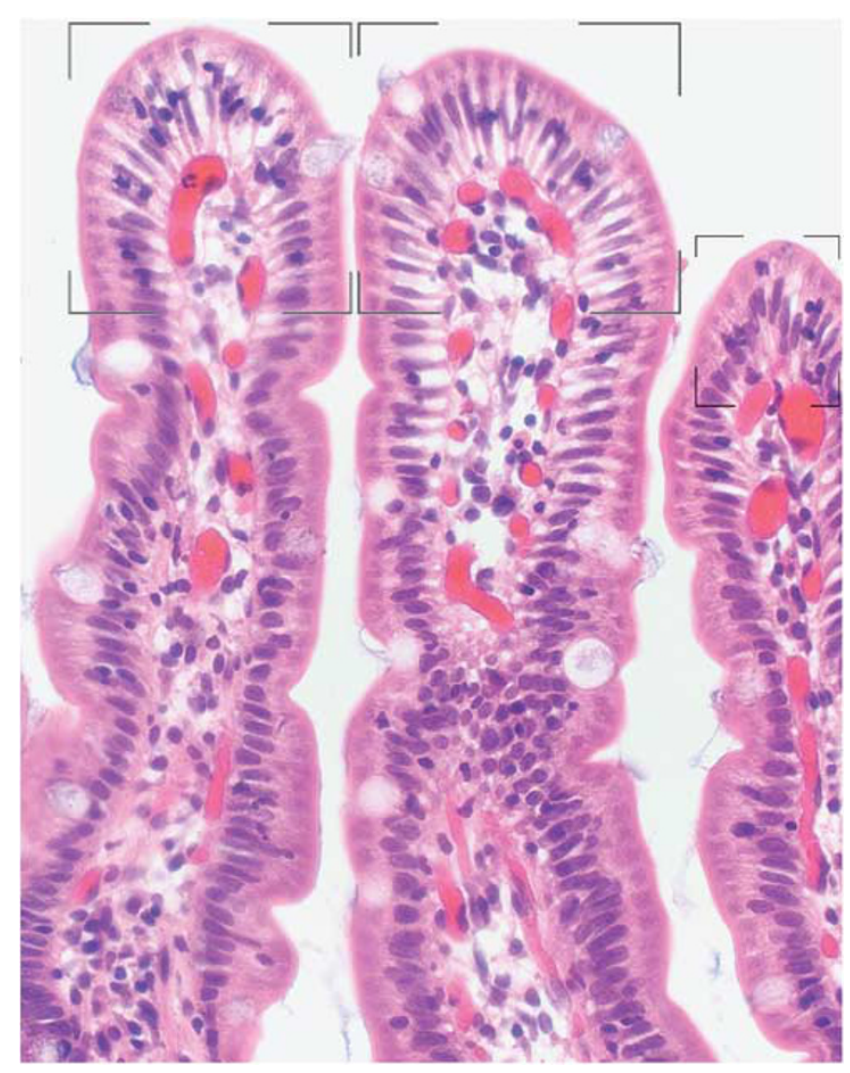

Figure 2 In this example, the increase of intraepithelial lymphocytes is particularly noticeable at the tips of the villi. This patient was eventually noted to have elevated IgA tissue transglutaminase.

gluten sensitivity. In all, the symptoms are alleviated when wheat and gluten are excluded from the diet. ${ }^{27}$

The prevalence of nonceliac gluten sensitivity has been between 0.55 and $6 \%$ of the population. This wide range may indicate confusion in correctly classifying patients; the lack of validated diagnostic tests for an accurate estimation; and/or selection bias. Its pathogenesis remains unclear, and the presenta- 
tion includes a combination of IBS-like symptoms (for example, bloating, abdominal pain, diarrhea, and/or constipation), and systemic manifestations (for example, headache, fatigue, and anemia). ${ }^{27-29}$

The diagnosis of nonceliac gluten sensitivity is made by excluding GSE. Morphologically, it is not associated with villous blunting. However, whereas some authors state that the absence of histologic alterations is an essential diagnostic parameter, others have reported a high frequency of duodenal lymphocytosis (90\%), sometimes associated with increased eosinophilic infiltrate. ${ }^{28,30}$ Colonic biopsies also may reveal an infiltration of the epithelium and lamina propria by eosinophils (although the architecture is preserved) in about two-thirds of the patients. ${ }^{30}$ Alternatively, increased colonic IEL infiltration is noted in only $25 \%$ of the patients. Importantly, these cells are T-cell receptoralpha/beta IELs, whereas T-cell receptor-gamma/ delta IELs are only noted in GSE. ${ }^{29}$

\section{Hypersensitivity to Other Alimentary Proteins}

Hypersensitivity to non-gluten components of foods such as gluten-free cereals, cow's milk, soy products, fish, rice, and chicken has been associated with duodenal lymphocytosis in some affected patients. Variable degrees of villous alteration with crypt hyperplasia can be seen. Reported diagnostic clues include increased eosinophils and other clinical manifestations of an allergic phenotype. ${ }^{31-}$ 34 Duodenal lymphocytosis in autistic children, whether or not associated with the lactase deficiency frequently recorded in these patients, also has been observed. ${ }^{35}$

\section{Infections}

In $6-14 \%$ of cases, duodenal lymphocytosis is associated with Helicobacter pylori gastritis. ${ }^{15,16,36}$ The increased IELs usually display a patchy distribution in the proximal duodenum. Another diagnostic clue is obviously the detection of chronic active gastritis with $H$. pylori organisms. Furthermore, a subset of these cases resolves when the infection is eradicated. ${ }^{36-38}$ Tropical enteropathy (sprue), which may present with normal villi but increased IELs, is diagnosed in patients who have lived in tropical regions, even for a limited time. The morphology is identical to that of celiac disease (Figure 3). However, the detection of severe ileal involvement (if biopsied) will be helpful in considering this condition. Increased eosinophils are also a noted histologic clue in the appropriate clinical setting. ${ }^{39}$ Tropical sprue is suspected to be caused by chronic infection by enteric enterogenic coliform. ${ }^{39}$ This hypothesis is confirmed indirectly by a temporal relationship to bouts of acute diarrhea and a good response to a variety of antibiotics, vitamin B12, and folate therapy. Parasitic infections

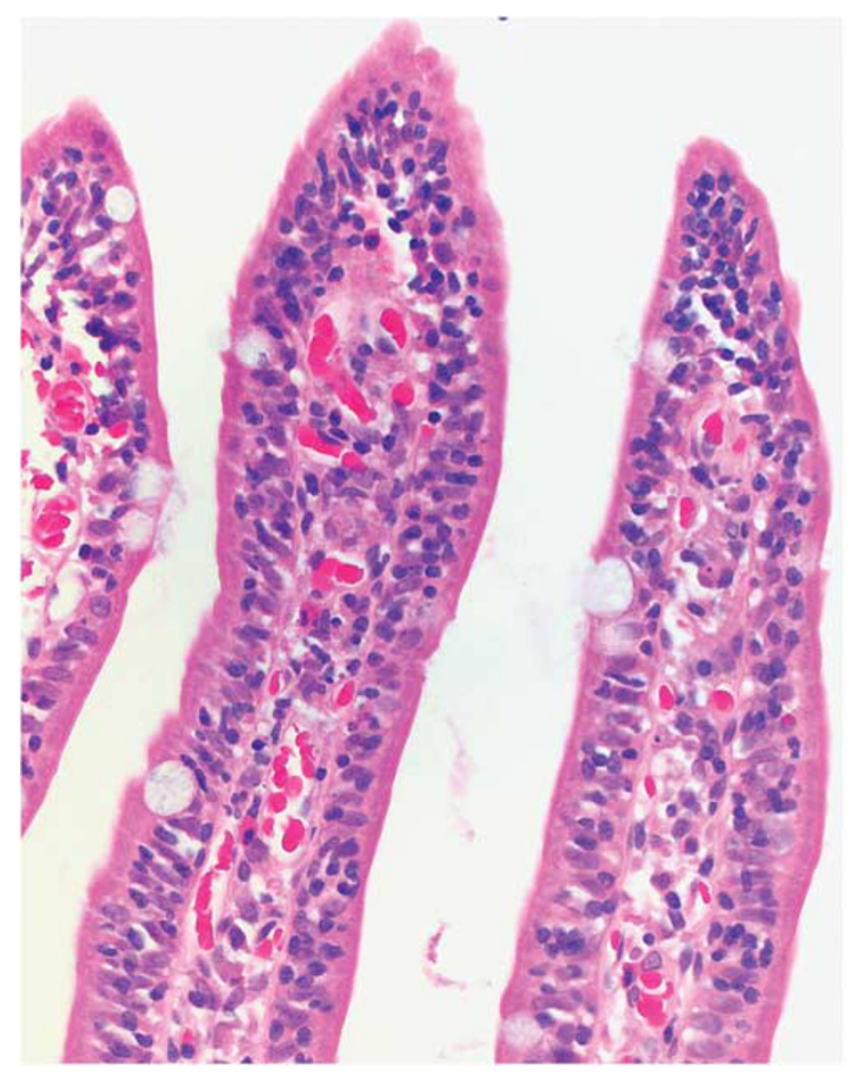

Figure 3 Tropical sprue in an immigrant from Southeast Asia. Notably, no marked eosinophilic infiltration is detected. Jejunal biopsies, clinical suspicion, and negative serology will help to rule out celiac disease.

such as Giardia lamblia and Cryptosporidium also can be associated with increased lymphocytic exocytosis (Figure 4). Careful review of the epithelial lining will be critical to the diagnosis of these etiologies. Common eosinophilia is reported but may not always be a distinctive feature. Elevated IEL counts also can be seen post-viral enteritis, ${ }^{40,41}$ although some degree of villous atrophy is usually recognized (Figure 5). In such cases, appropriate clinical communication is obviously cardinal to establish a timeline between the suspected viral episodes and the intestinal symptomatology.

Bacterial overgrowth, whether related to gastric hypochlorhydria or intestinal dysmotility, has been associated with an increase in IELs (in the absence of villous atrophy) compared with control biopsies. ${ }^{42}$ However, only some cases in that study had an IEL density above what is currently considered the normal range. In the study by Kakar et al, ${ }^{13}$ two cases $(4.5 \%)$ of intraepithelial lymphocytosis were related to bacterial overgrowth (Figure 6). Conditions causing stagnation or recirculation of the intestinal contents are predisposing factors. Associated conditions include anatomic abnormalities (diverticula, anastomosis, and stricture), anomalies of motility (for example, diabetic neuropathy), as well as a multifactorial condition (chronic pancreatitis and irritable bowel syndrome). 


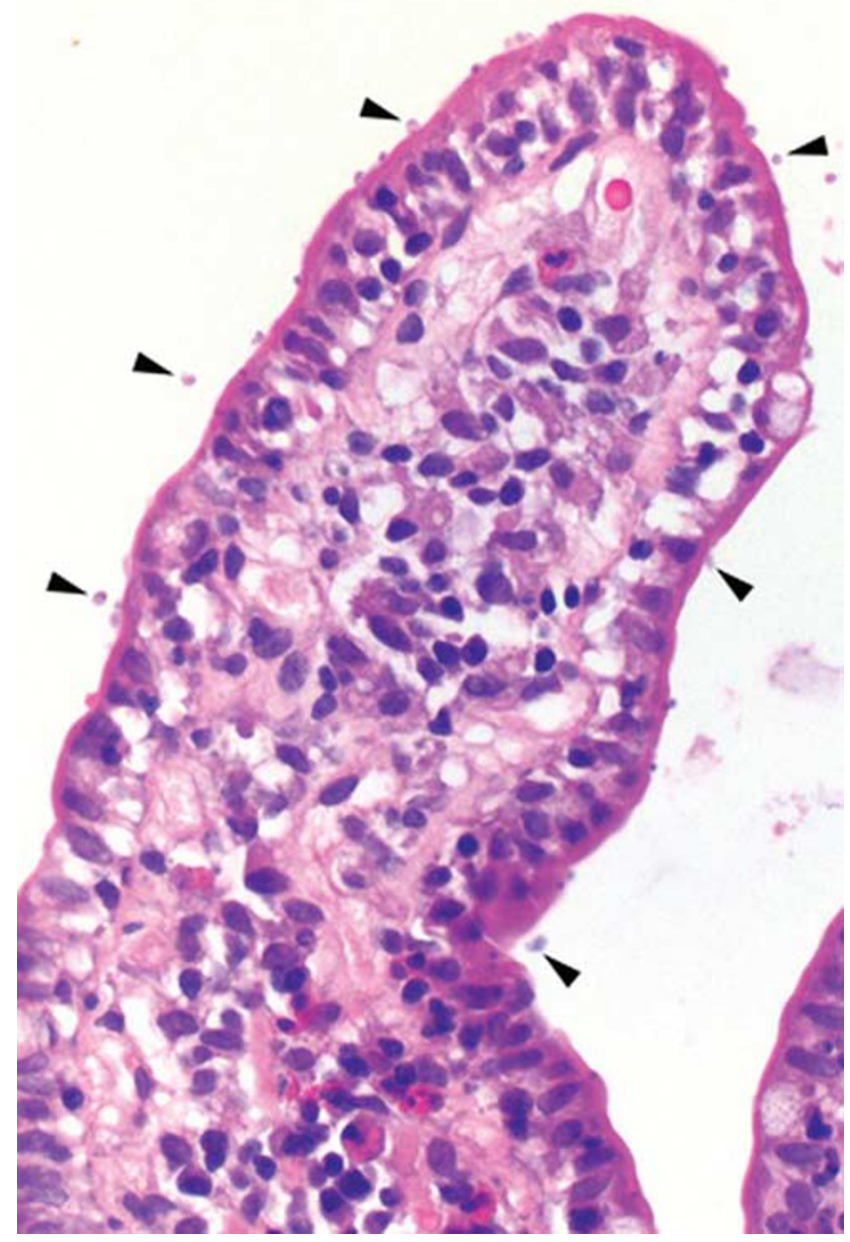

Figure 4 Cryptosporidiosis with intraepithelial lymphocytosis. The parasite is easily detectable adhering to the apex of epithelial cells (arrowhead).

\section{Drugs}

NSAIDs have been noted in frequent association with duodenal lymphocytosis, with their use reported in $14-29.5 \%$ of patients. ${ }^{4,13}$ It is hypothesized that increased use in preventive care (for example, cardiology) and liberal access account for the increased incidence in the association. In a recent study, Brown et $a l^{39}$ found that $20 \%$ of patients taking a proton pump inhibitor had elevated IELs. The relative hypochlorhydria with bacterial overgrowth having a role in that setting could be hypothesized. However, this was not confirmed recently by Shmidt et $a .^{4}$ Recently, it has been recognized that olmesartan, an angiotensin II receptor antagonist, can lead to significant lymphocytic exocytosis; however, it is commonly associated with various degrees of blunting. ${ }^{43}$

\section{Autoimmune Conditions}

It is not unexpected that disorders of immune regulation can be associated with elevated IELs and various degrees of villous atrophy. This was the case

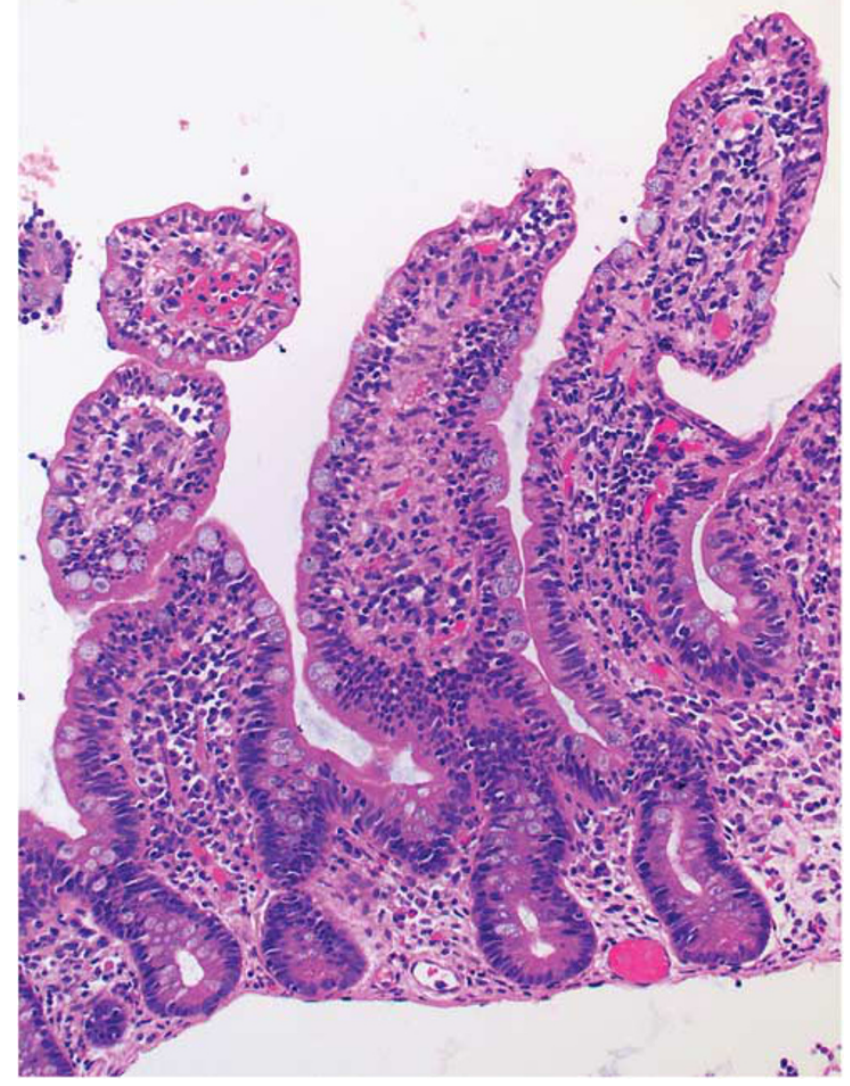

Figure 5 Example of post-viral intraepithelial lymphocytosis in a patient with a very suggestive clinical history. Furthermore, celiac serology was negative, and no increased intraepithelial lymphocytes were present on two subsequent biopsies.

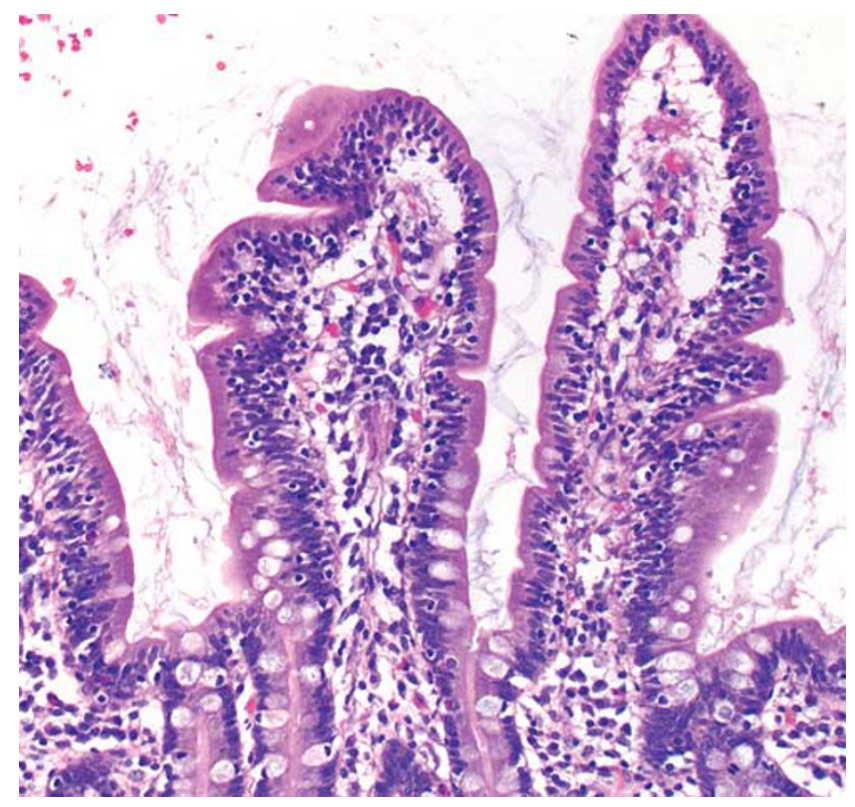

Figure 6 Bacterial overgrowth is commonly associated with increased intraepithelial lymphocytes. However, only a few cases show distinct increase such as this one demonstrates. Although the histology is not characteristic, clinical information (for example, older age, small-bowel diverticula, pancreatitis, and so on) may steer the differential diagnosis appropriately. 


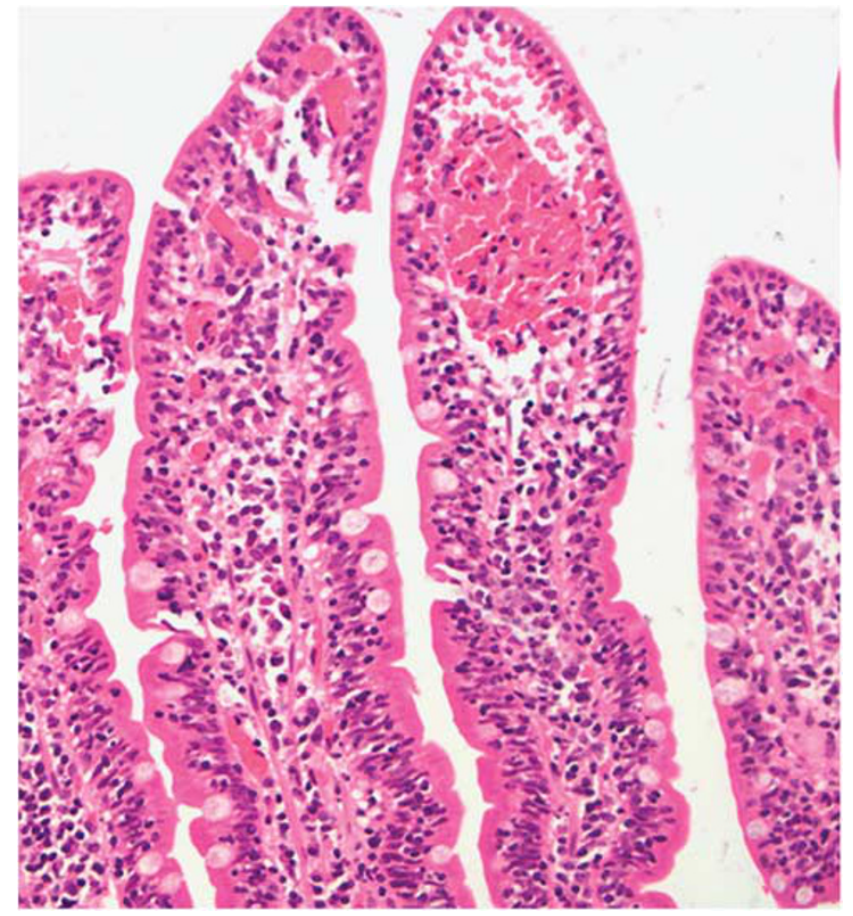

Figure 7 Crohn's disease. Numerous intraepithelial lymphocytes are evident along the entire length of the villi. The patient was TTG- and HLADQ2-negative, and also had active ileitis at the time of biopsy.

in $14 \%$ of patients in the series by Kakar et $a 1^{13}$ who had an immune dysregulation condition. Reported conditions include Hashimoto's thyroiditis, Grave's disease, rheumatoid arthritis, psoriasis, multiple sclerosis, and systemic lupus erythematosus. ${ }^{8,13}$ Intestinal intraepithelial lymphocytosis in the setting of glomerulonephritis is also reported, particularly when presenting with nephrotic syndrome. ${ }^{44}$

Increased IELs in the proximal small intestine often are detected in patients with hypogammaglobulinemia, whether because of IgA deficiency or common variable immunodeficiency. ${ }^{45}$ Villous atrophy can be mild. Morphologic clues to the diagnosis can include reduced numbers of plasma cells, frequent parasitic infection (for example, Giardia), glandular apoptosis, and lymphoid follicle formation. ${ }^{46}$

Chronic idiopathic inflammatory bowel disease can be associated with duodenal intraepithelial lymphocytosis. ${ }^{12,13,47}$ Duodenal intraepithelial lymphocytosis also has been noted in association with both lymphocytic and collagenous colitis. Notably, in many cases, the association appears to be exclusive of gluten sensitivity, despite the recognized association of both variants of microscopic colitis with celiac disease. ${ }^{48-50}$

Interestingly, the finding of duodenal intraepithelial lymphocytosis in patients with Crohn's disease can be observed concurrent with full-blown active disease but may also precede active Crohn enteritis (Figure 7 ). ${ }^{12}$
Graft versus host disease also, although uncommonly, can display prominent numbers of IELs. ${ }^{51}$ The finding of epithelial cell apoptosis and some degrees of architectural disturbance together with a distinct clinical setting allows for correct diagnosis.

\section{Autoimmune Enteropathy}

This is a rare condition characterized by severe and protracted diarrhea with weight loss from malabsorption and immune-mediated changes to intestinal mucosa. This disorder generally occurs among infants and young children, although some cases have been reported in adults. Small intestinal histopathology usually encompasses various degrees of villous atrophy, lymphoplasmacytic infiltration of the lamina propria, and crypt hyperplasia. Cases with preserved architecture result from early diagnosis or successful therapy. However, IELs are more numerous in crypts than in the surface and remaining villus tips. There is also usually marked crypt damage with apoptosis. ${ }^{52}$

\section{Neoplasias}

Type 2 refractory celiac disease (RCD type 2) is a known precursor lesion of enteropathy-associated T-cell lymphoma. The morphology is of a minimally or non-atrophic small intestinal mucosa. Special studies will be diagnostic, as they demonstrate a clonal population of IELs with an abnormal phenotype. RCD type 2 ought to be considered in the diagnosis of duodenal lymphocytosis in the setting of known celiac disease patients who lack histologic and/or clinical improvement despite prolonged gluten-free diet. ${ }^{53}$

\section{Intraepithelial Lymphocytosis Without Definitive Diagnosis}

In many cases, the detection of duodenal intraepithelial lymphocytosis may not lead to a recognizable specific etiology. This category represents between 7 and 34\% of the cases diagnosed. ${ }^{13-16,36}$ Some of these patients meet clinical criteria for irritable bowel syndrome and may respond symptomatically to a gluten-free diet. Whether these patients have a subtle form of gluten sensitivity remains uncertain, although there is some experimental support for this suggestion. ${ }^{54}$

\section{Conclusions}

Up to $2.5 \%$ of proximal small intestinal mucosal biopsies display increased IELs ( > 25 IELs/100 IELs) in the absence of villous architectural change. In most cases, this is because of immunological activation of the lymphocytes that are normally resident in the epithelium. The causes for this increase in number of IELs are multiple and include reactions to intraluminal antigens and small intestinal 
manifestations of autoimmune or other allied diseases. Gluten-related disorders are the most common cause, accounting for $9-40 \%$ of cases. ${ }^{13,14,17}$ The establishment of a diagnosis of celiac disease and other gluten-related disorders can be clinically difficult and relies on a weighted assessment of clinical, serological, and histopathological data. Pathologists can help by highlighting cases that have a uniform distribution of IELs over the villus length as being more likely to represent gluten sensitivity than those showing increased numbers but in a persisting decrescendo pattern.

\section{Disclosure/conflict of interest}

The authors declare no conflict of interest.

\section{References}

1 Lee SK, Green PH. Celiac sprue (the great modern-day imposter). Curr Opin Rheumatol 2006;18:101-107.

2 Sanders DS, Carter MJ, Hurlstone DP, et al. Association of adult coeliac disease with irritable bowel syndrome: A case-control study in patients fulfilling ROME II criteria referred to secondary care. Lancet 2001;358: 1504-1508.

3 Green PH, Jabri B. Celiac disease. Annu Rev Med 2006;57:207-221.

4 Shmidt E, Smyrk TC, Boswell CL, et al. Increasing duodenal intraepithelial lymphocytosis found at upper endoscopy: Time trends and associations. Gastrointest Endosc 2014;80:105-111.

5 Arato A, Hacsek G, Savilahti E. Immunohistochemical findings in the jejunal mucosa of patients with coeliac disease. Scand J Gastroenterol Suppl 1998;228:3-10.

6 Veress B, Franzen L, Bodin L, et al. Duodenal intraepithelial lymphocyte-count revisited. Scand J Gastroenterol 2004;39:138-144.

7 Hayat M, Cairns A, Dixon MF, et al. Quantitation of intraepithelial lymphocytes in human duodenum: What is normal? J Clin Pathol 2002;55:393-394.

8 Ferguson A. Intraepithelial lymphocytes of the small intestine. Gut 1977;18:921-937.

9 Goldstein NS, Underhill J. Morphologic features suggestive of gluten sensitivity in architecturally normal duodenal biopsy specimens. Am J Clin Pathol 2001;116:63-71.

10 Jarvinen TT, Collin P, Rasmussen M, et al. Villous tip intraepithelial lymphocytes as markers of early-stage coeliac disease. Scand J Gastroenterol 2004;39:428-433.

11 Mino M, Lauwers GY. Role of lymphocytic immunophenotyping in the diagnosis of gluten-sensitive enteropathy with preserved villous architecture. Am J Surg Pathol 2003;27:1237-1242.

12 Goldstein NS. Proximal small-bowel mucosal villous intraepithelial lymphocytes. Histopathology 2004;44: 199-205.

13 Kakar S, Nehra V, Murray JA, et al. Significance of intraepithelial lymphocytosis in small bowel biopsy samples with normal mucosal architecture. Am J Gastroenterol 2003;98:2027-2033.

14 Mahadeva S, Wyatt JI, Howdle PD. Is a raised intraepithelial lymphocyte count with normal duode- nal villous architecture clinically relevant? J Clin Pathol 2002;55:424-428.

15 Aziz I, Evans KE, Hopper AD, et al. A prospective study into the aetiology of lymphocytic duodenosis. Aliment Pharmacol Ther 2010;32:1392-1397.

16 Hammer STG, Maneerattanaporn M, Rude K, et al. Duodenal lymphocytosis with normal villous architecture: How often is it celiac disease? Vol 23. 2010, pp 146A-147A.

17 Wahab PJ, Crusius JB, Meijer JW, et al. Gluten challenge in borderline gluten-sensitive enteropathy. Am J Gastroenterol 2001;96:1464-1469.

18 Biagi F, Luinetti O, Campanella J, et al. Intraepithelial lymphocytes in the villous tip: Do they indicate potential coeliac disease? J Clin Pathol 2004;57: 835-839.

19 Hudacko R, Kathy Zhou X, Yantiss RK. Immunohistochemical stains for CD3 and CD8 do not improve detection of gluten-sensitive enteropathy in duodenal biopsies. Mod Pathol 2013;26:1241-1245.

20 Marsh MN. Screening for latent gluten sensitivity: Questions many, but answers few. Eur J Gastroenterol Hepatol 1996;8:3-6.

21 Ciclitira PJ, King AL, Fraser JS. AGA technical review on celiac sprue. american gastroenterological association. Gastroenterology 2001;120:1526-1540.

22 Husby S, Koletzko S, Korponay-Szabo IR, et al. European society for pediatric gastroenterology, hepatology, and nutrition guidelines for the diagnosis of coeliac disease. J Pediatr Gastroenterol Nutr 2012;54:136-160.

23 Tursi A, Brandimarte G, Giorgetti G, et al. Low prevalence of antigliadin and anti-endomysium antibodies in subclinical/silent celiac disease. Am J Gastroenterol 2001;96:1507-1510.

24 Murray JA, Herlein J, Mitros F, et al. Serologic testing for celiac disease in the united states: Results of a multilaboratory comparison study. Clin Diagn Lab Immunol 2000;7:584-587.

25 Licata A, Cappello M, Arini A, et al. Serology in adults with celiac disease: Limited accuracy in patients with mild histological lesions. Intern Emerg Med 2012;7:337-342.

26 Murdock AM, Johnston SD. Diagnostic criteria for coeliac disease: time for change? Eur J Gastroenterol Hepatol 2005;17:41-43.

27 Mansueto P, Seidita A, D’Alcamo A, et al. Non-celiac gluten sensitivity: Literature review. J Am Coll Nutr 2014;33:39-54.

28 Tonutti E, Bizzaro N. Diagnosis and classification of celiac disease and gluten sensitivity. Autoimmun Rev 2014;13:472-476.

29 Catassi C, Bai JC, Bonaz B, et al. Non-celiac gluten sensitivity: the new frontier of gluten related disorders. Nutrients 2013;5:3839-3853.

30 Carroccio A, Mansueto $\mathrm{P}$, Iacono $\mathrm{G}$, et al. Non-celiac wheat sensitivity diagnosed by doubleblind placebo-controlled challenge: Exploring a new clinical entity. Am J Gastroenterol 2012;107: 1898-1906.

31 Kaukinen K, Turjanmaa K, Maki M, et al. Intolerance to cereals is not specific for coeliac disease. Scand J Gastroenterol 2000;35:942-946.

32 Kokkonen J, Holm K, Karttunen TJ, et al. Children with untreated food allergy express a relative increment in the density of duodenal gammadelta + T cells. Scand J Gastroenterol 2000;35:1137-1142. 
33 Vitoria JC, Camarero C, Sojo A, et al. Enteropathy related to fish, rice, and chicken. Arch Dis Child 1982; $57: 44-48$

34 Savilahti E. Food-induced malabsorption syndromes. J Pediatr Gastroenterol Nutr 2000;30 (Suppl):S61-S66.

35 Ashwood P, Anthony A, Torrente F, et al. Spontaneous mucosal lymphocyte cytokine profiles in children with autism and gastrointestinal symptoms: Mucosal immune activation and reduced counter regulatory interleukin-10. J Clin Immunol 2004;24:664-673.

36 Shmidt E, Smyrk TC, Faubion WA, et al. Duodenal intraepithelial lymphocytosis with normal villous architecture in pediatric patients: Mayo clinic experience, 2000-2009. J Pediatr Gastroenterol Nutr 2013; $56: 51-55$

37 Biagi F, Bianchi PI, Campanella J, et al. The prevalence and the causes of minimal intestinal lesions in patients complaining of symptoms suggestive of enteropathy: a follow-up study. J Clin Pathol 2008;61:1116-1118.

38 Memeo L, Jhang J, Hibshoosh $\mathrm{H}$, et al. Duodenal intraepithelial lymphocytosis with normal villous architecture: Common occurrence in $H$. pylori gastritis. Mod Pathol 2005;18:1134-1144.

39 Brown IS, Bettington A, Bettington M, et al. Tropical sprue: revisiting an underrecognized disease. Am J Surg Pathol 2014;38:666-672.

40 Montgomery RD, Shearer AC. The cell population of the upper jejunal mucosa in tropical sprue and postinfective malabsorption. Gut 1974;15:387-391.

41 Ferguson A, McClure JP, Townley RR. Intraepithelial lymphocyte counts in small intestinal biopsies from children with diarrhoea. Acta Paediatr Scand 1976; 65:541-546.

42 Riordan SM, McIver CJ, Wakefield D, et al. Small intestinal mucosal immunity and morphometry in luminal overgrowth of indigenous gut flora. Am J Gastroenterol 2001;96:494-500.

43 Rubio-Tapia A, Herman ML, Ludvigsson JF, et al. Severe spruelike enteropathy associated with olmesartan. Mayo Clin Proc 2012;87:732-738.

44 Rostoker G, Delchier JC, Chaumette MT. Increased intestinal intra-epithelial $\mathrm{T}$ lymphocytes in primary glomerulonephritis: a role of oral tolerance breakdown in the pathophysiology of human primary glomerulonephritides? Nephrol Dial Transplant 2001;16: 513-517.

45 Daniels JA, Lederman HM, Maitra A, et al. Gastrointestinal tract pathology in patients with common variable immunodeficiency (CVID): a clinicopathologic study and review. Am J Surg Pathol 2007;31: 1800-1812.

46 Washington K, Stenzel TT, Buckley RH, et al. Gastrointestinal pathology in patients with common variable immunodeficiency and X-linked agammaglobulinemia. Am J Surg Pathol 1996;20:1240-1252.

47 Tobin JM, Sinha B, Ramani P, et al. Upper gastrointestinal mucosal disease in pediatric crohn disease and ulcerative colitis: A blinded, controlled study. J Pediatr Gastroenterol Nutr 2001;32:443-448.

48 Wang N, Dumot JA, Achkar E, et al. Colonic epithelial lymphocytosis without a thickened subepithelial collagen table: A clinicopathologic study of 40 cases supporting a heterogeneous entity. Am J Surg Pathol 1999;23:1068-1074.

49 Freeman HJ. Collagenous colitis as the presenting feature of biopsy-defined celiac disease. J Clin Gastroenterol 2004;38:664-668.

50 Koskela RM, Niemela SE, Karttunen TJ, et al. Clinical characteristics of collagenous and lymphocytic colitis. Scand J Gastroenterol 2004;39:837-845.

51 Goldman H, Antonioli DA. Mucosal biopsy of the esophagus, stomach, and proximal duodenum. Hum Pathol 1982;13:423-448.

52 Masia R, Peyton S, Lauwers GY, et al. Gastrointestinal biopsy findings of autoimmune enteropathy: A review of 25 cases. Am J Surg Pathol 2014;38:1319-1329.

53 Malamut G, Afchain P, Verkarre V, et al. Presentation and long-term follow-up of refractory celiac disease: Comparison of type I with type II. Gastroenterology 2009;136:81-90.

54 Wahnschaffe U, Ullrich R, Riecken EO, et al. Celiac disease-like abnormalities in a subgroup of patients with irritable bowel syndrome. Gastroenterology 2001; 121:1329-1338. 